Copyright (C) 2015 by Academic Publishing House Researcher

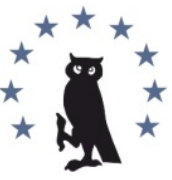

Published in the Russian Federation

European Researcher

Has been issued since 2010.

ISSN 2219-8229

E-ISSN 2224-0136

Vol. 93, Is. 4, pp. 282-289, 2015

DOI: 10.13187/ er.2015.93.282

www.erjournal.ru

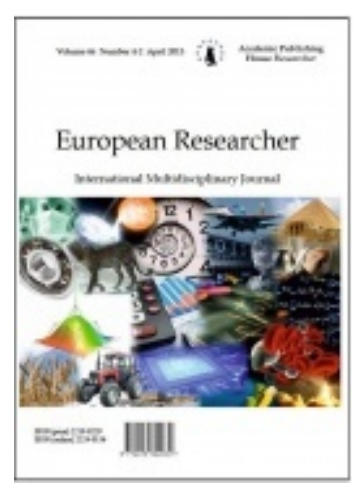

UDC 332.36

\title{
The Current Trends in the Residential Development of Landscape and Geomorphological Tiers of the Republic of Dagestan
}

\author{
${ }^{1}$ Vitaly V. Bratkov \\ 2,3 Zagir V. Ataev
}

\author{
${ }^{1}$ Moscow State University of Geodesy and Cartography, Russian Federation \\ 4, Gorokhovsky pereulok, Moscow, 105064 \\ Doctor of Geographical Sciences,Professor \\ E-mail: vratkov@mail.ru \\ 2 Dagestan State Pedagogical University, Russian Federation \\ 57, Yaragskogo street, Makhachkala, 367003 \\ ${ }^{3}$ Caspian Institute of Biological Resources of Dagestan Scientific Center, \\ Russian Academy of Sciences, Russian Federation \\ 45, Gadzhiyev street, Makhachkala, 367000 \\ $\mathrm{PhD}$ (Geography), Professor \\ E-mail: zagir05@mail.ru
}

\begin{abstract}
The article reveals trends in the residential load within the landscape and geomorphological tiers of the Republic of Dagestan. Analysis is based on the comparison of the areas of human settlements of different categories on the medium-sized cards editions mid-1980s and early 2000s. The article identifies tendencies of changes in the area of human settlements and their categories of high-geomorphological tiers. During the period under review the residential load decreased only within highland tier, while in others it has increased. Mostly the increase in the load is typical of the seaside and plain tiers where Makhachkala Caspian agglomeration is actively formed.

Keywords: the Republic of Dagestan; landscape and geomorphological tier; human settlement; residential landscape; residential load.

\section{Введение}

Республика Дагестан, как и большинство других субъектов Северо-Кавказского федерального округа, характеризуется устойчивым ростом населения. Этот процесс способствует преобразованию природных ландшафтов в селитебные. К селитебным ландшафтам традиционно относятся ландшафты населенных пунктов, а классификация этих ландшафтов основывается в главных чертах на категориях населенных пунктов (сельских и городских) [11; 12].
\end{abstract}

\section{Материалы и методы}

Для выявления тенденций изменения селитебной освоенности ландшафтногеоморфологических ярусов Дагестана были определены площади населенных пунктов по 
топографическим картам масштаба 1:200 ооо. Для изучаемой территории имеются карты, выпущенные в середине и во второй половине 1980-х годов, а также в начале 2000-х годов. Нами принято, что они отражают систему населенных пунктов, сложившуюся условно на 1990 и 2000 гг. В соответствии с общепринятыми классификациями, населенные пункты отнесены к следующим категориям: города, поселки городского типа, поселки дачного и садового типа, поселки сельского типа. В результате оцифровки этих объектов в программной среде MapInfo стало возможным сопоставить слой, содержащий сведения о ландшафтно-геоморфологических ярусах территории, со слоями населенных пунктов по состоянию на 1990 и 2000 гг.

\section{Обсуждение}

Для территории Северного Кавказа и Республики Дагестан теоретические и методические аспекты селитебной освоенности ландшафтов рассматриваются в работах $[2 ; 3 ; 5 ; 6 ; 8 ; 10 ; 13 ; 14]$. Подобная работа была проделана С.В. Панковым для территории Тамбовской области [15]. Ниже основное внимание уделено анализу селитебной освоенности ландшафтно-геоморфологических ярусов Республики Дагестан.

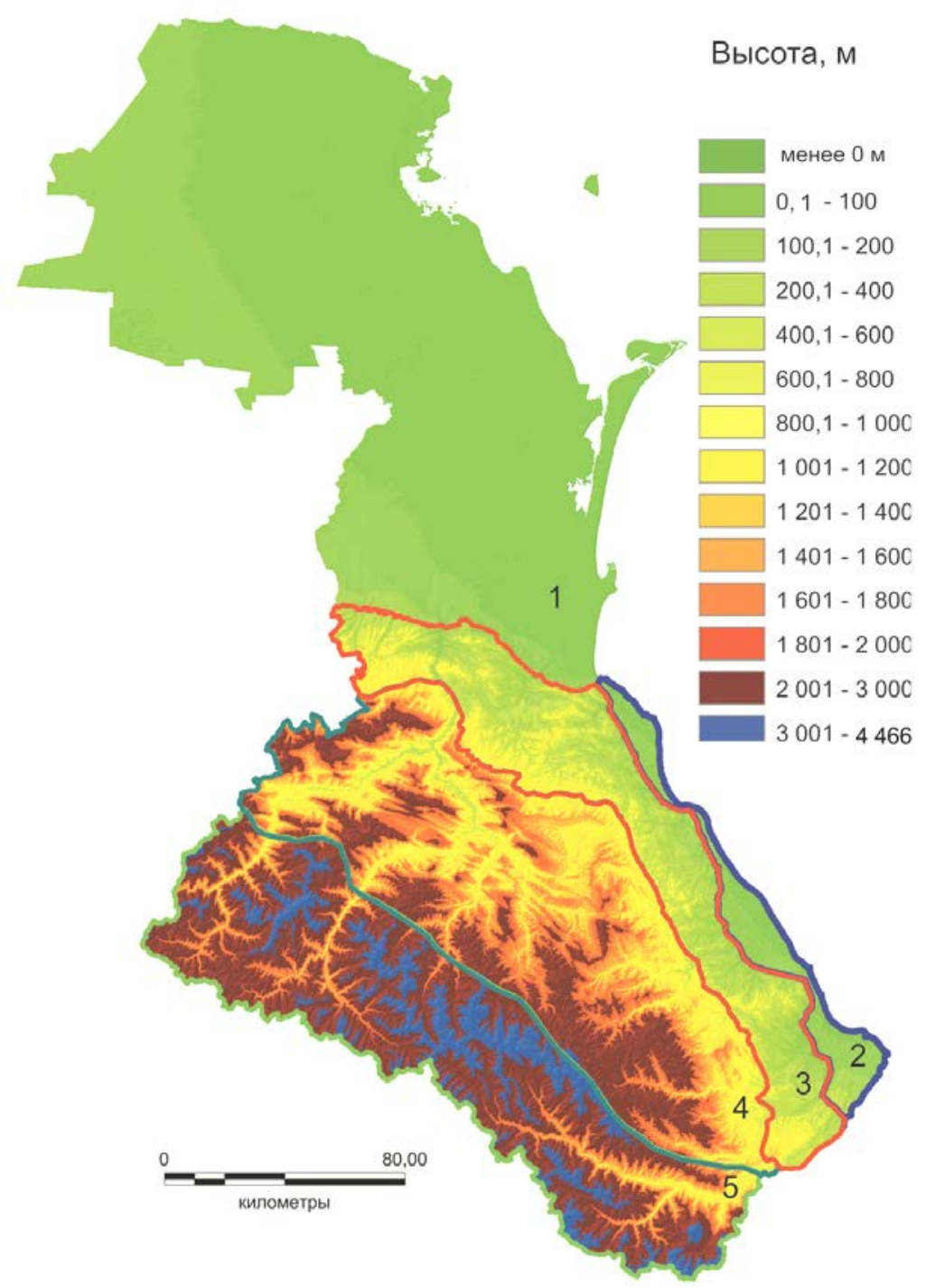

Puc. 1. Ландшафтно-геоморфологические ярусы Республики Дагестан (цифры соответствуют номерам ландшафтно-геморфологических ярусов в тексте) 


\section{Результаты исследования}

На территории Республики Дагестан выделяются следующие ландшафтногеоморфологические ярусы (рис. 1) [1; 7]:

1) Равнинный Дагестан;

2) Приморский Дагестан;

3) Предгорный Дагестан;

4) Внутригорный Дагестан;

5) Высокогорный Дагестан.

Равнинный Дагестан приурочен к Прикаспийской низменности и ее отдельным частям - Терско-Сулакской и Терско-Кумской низменностям. Здесь характерны высоты до $100 \mathrm{M}$, а уклон поверхностей редко превышает $2^{\circ}$. Преобладают полупустынные и сухостепные зональные, а также представлены интразональные дельтовые и пойменные ландшафты.

Приморский Дагестан представляет собой переходную часть от побережья Каспийского моря к предгорьям Большого Кавказа. Отметки высот здесь редко превышают 200 м, а также увеличивается доля поверхностей, имеющих уклон более $2^{\circ}$. Как и пределах Равнинного Дагестана, наиболее широко представлены полупустынные ландшафты, которые испытывают влияние как со стороны Большого Кавказа, так и Каспийского моря.

Предгорный Дагестан занимает площадь 5809 км² $^{2}$ преимущественно в интервале высот от 100 до 1200 м, хотя в отдельных местах поднимается и выше. С севера и востока он граничит с Равнинным и Приморским Дагестаном, которые, как уже отмечалось выше, представлены равнинами различного гипсометрического уровня. Уклоны поверхностей здесь чаще всего изменяются от о-2 до 10-15․ В полосе контакта с Внутригорным Дагестаном отмечается увеличение уклонов поверхностей (в основном до 15-25). В силу переходного положения и большого разнообразия местоположений, здесь отмечается значительное разнообразие коренных природно-территориальных комплексов: сухие и луговые степи, заросли кустарников, а также широколиственные леса.

Внутригорный Дагестан занимает высотные интервалы от 400-600 до 2000-3000 м, при этом на высотах до 1000 м располагается чуть более 12\% его территории. Основная его часть (60\%), приурочена к высотам 1000-2000 м, а доля территорий с отметками 2000-3000 м составляет 22\%. Наиболее широко здесь представлены склоны крутизной от 10-15 до 25-30 , на долю которых приходится 64\%. Менее крутые склоны (до 10 ${ }^{\circ}$ ) представлены чаще, чем более крутые, хотя на долю последних приходится более 10\%. К высотно-зональным здесь относятся горные умеренные гумидные ландшафты (широколиственные леса), горные холодно-умеренные (березовые и сосново-березовые леса, которые занимают склоны Большого Кавказа. Наряду с ними, в межгорных депрессиях, в связи с аридизацией климата, наиболее широко в пределах Северного Кавказа представлены горно-котловинные ландшафты. В целом для них характеры леса на циркуляционных склонах и ксерофитные сообщества - на солярных.

Высокогорный Дагестан располагается преимущественно в интервале высот от 2000 до 4466 м, так как на долю этого высотного интервала приходится более 80\% территории. Что касается уклона, то здесь наиболее часто встречаются поверхности с уклоном от 15-20 до $35-40^{\circ}$, доля которых составляет $78 \%$. Несмотря на это, здесь нередко встречаются склоны крутизной до 6-8 ${ }^{\circ}$ но доля наиболее крутых склонов все же выше, чем доля более пологих. Для этого высотного пояса характеры субальпийские и альпийские луга, а в наиболее возвышенных частях - снежники и ледники.

Что касается Внутригорного и Высокогорного Дагестана, то, как и в случае Равнинного и Приморской частей, заметно достаточно большое сходство между ними. Оно проявляется в том, что эти высотные ландшафтно-геоморфологические пояса занимают довольно близкие гипсометрические уровни. Для них также характерны склоны с сопоставимыми значениями крутизны. В целом в обоих случаях заметно увеличение крутизны склонов по мере роста абсолютной высоты, что объясняется особенностями геологического строения территории. 
Как показал проведенный анализ, наиболее разнообразными условиями характеризуется Предгорный Дагестан: здесь широко представлены местоположения, типичные как для равнинной части, так и для горной [4]. На наиболее низкие гипсометрические уровни (200-400 м) приходится 35\% территории; на склоны, крутизной 0-6 ${ }^{\circ}$, которые более характерны для равнин, приходится 46\%. Вместе с тем, здесь довольно широко представлены и более крутые склоны, типичные для Внутригорного и Высокогорного Дагестана.

Площадь населенных пунктов (НП) по состоянию на 1990 и 2000 гг. иллюстрируют табл. 1 и рис. 2.

Таблица 1

Площади населенных пунктов Республики Дагестан в 1990 и 2000 гг.

\begin{tabular}{|c|c|c|c|c|c|c|c|}
\hline $\begin{array}{c}\text { Ландшафтно- } \\
\text { геоморфологические } \\
\text { ярусы }\end{array}$ & 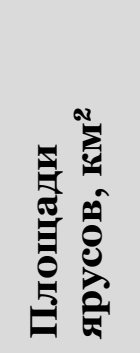 & 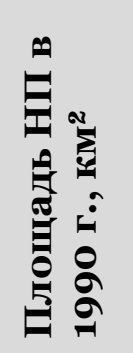 & 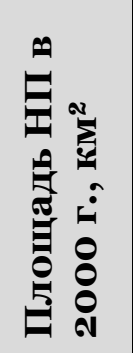 & 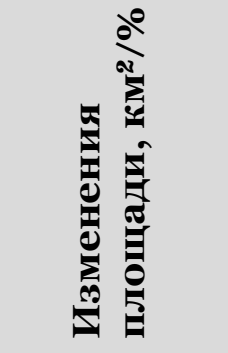 & 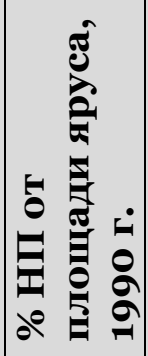 & 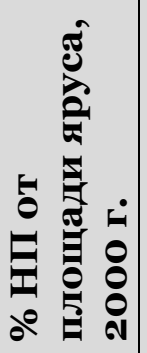 & 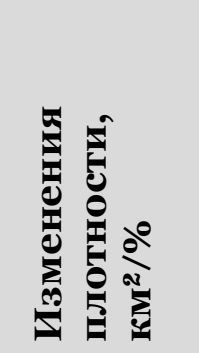 \\
\hline Равнинный & 21570 & 288,4 & 380,2 & $91,7 / 31,8$ & 1,3 & 1,8 & $0,4 / 31,8$ \\
\hline Приморский & 1480 & 108,3 & 162,6 & $54,3 / 50,1$ & 7,3 & 11,0 & $3,7 / 50,1$ \\
\hline Предгорный & 5809 & 134,1 & 175,9 & $41,8 / 31,2$ & 2,3 & 3,0 & $0,7 / 31,2$ \\
\hline Внутригорный & 11610 & 162,9 & 191,6 & $28,7 / 17,6$ & 1,4 & 1,7 & $0,3 / 17,6$ \\
\hline \multirow[t]{2}{*}{ Высокогорный } & 9629 & 66,4 & 42,9 & $-23,4 /-35,3$ & 0,7 & 0,4 & $-0,3 /-35,3$ \\
\hline & 50098 & 760,2 & 953,2 & $193,0 / 25,4$ & 1,5 & 1,9 & $0,4 / 25,4$ \\
\hline
\end{tabular}

Примечание: в состав Равнинного Дагестана не включена островная часть в силу отсутствия здесь постоянных НП, поэтому приведенная площадь не соответствует общей площади Республики Дагестан.
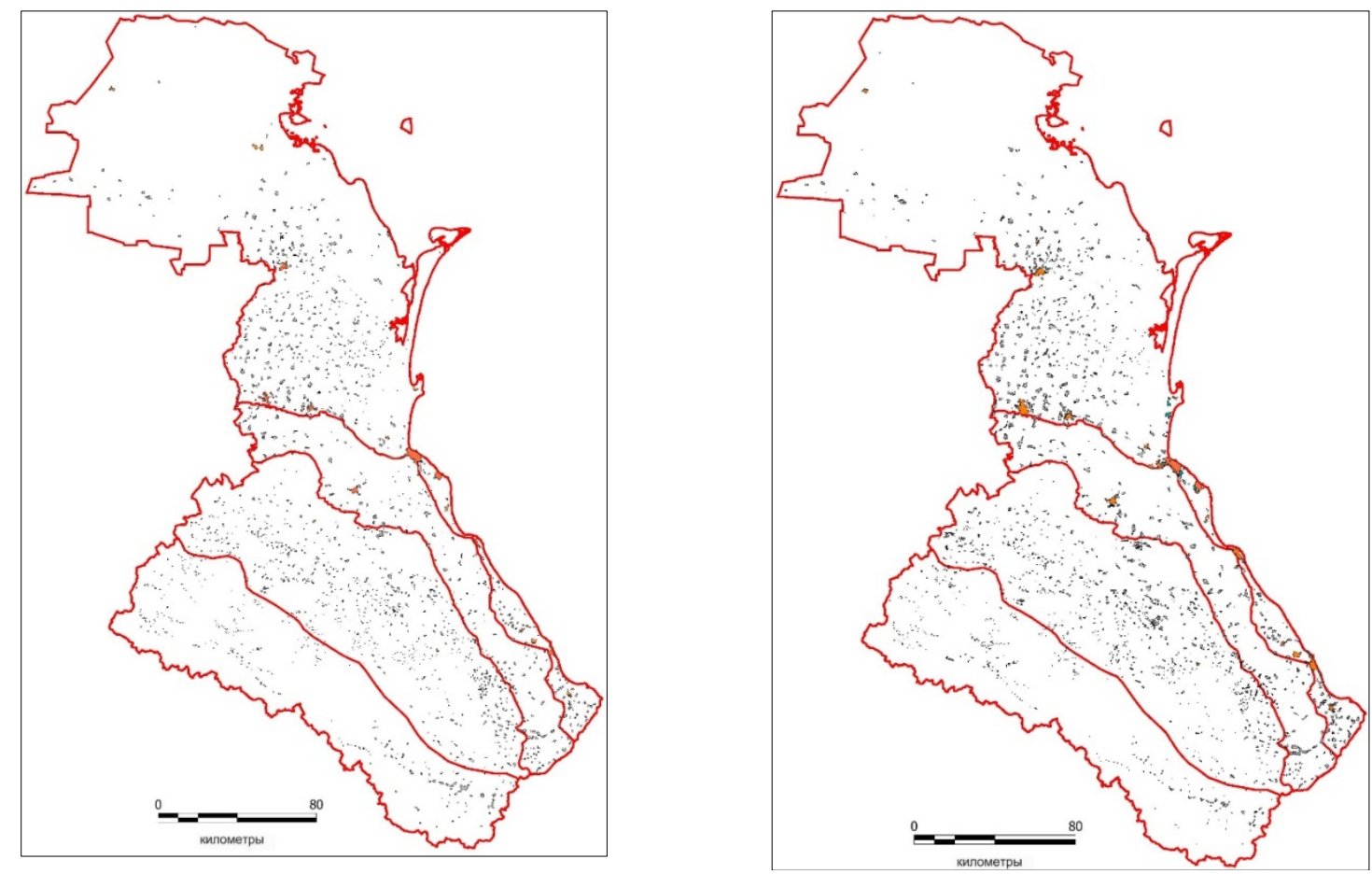

Puc. 2. Площади населенных пунктов Республики Дагестан в 1990 (слева) и 2000 гг. (справа) 
По состоянию на 1990 г. населенные пункты занимали территорию 760,2 км², а их доля составляла 1,5\% площади Республики Дагестан. При этом наибольшая площадь населенных пунктов была в пределах равнинного ландшафтно-геоморфологического яруса - 288,4 км², или 1,3\%. Вторым по заселенности являлся внутригорный ярус, где доля населенных пунктов была даже выше, чем в равнинном (1,4\%), хотя их площадь была меньше - 162,9 км². Несколько меньшую площадь населенные пункты занимали в пределах предгорного яруса - 134,1 км² , при этом освоенность этого яруса была выше, чем равнинного и внутригорного $(2,4 \%)$. В пределах приморского яруса площадь населенных пунктов составляла 108,3 км², но, в сочетании с минимальной по сравнению с другими ярусами, здесь отмечалась максимальная доля поселений на всей территории Республики Дагестан 7,3 км$^{2}$. Наконец, минимально был освоен высокогорный ярус, где населенные пункты располагались лишь на площади в 66,4 км², что составляло лишь 0,7\%. То есть, с точки зрения площади поселений ландшафтно-геоморфологические яруса ранжируются довольно логично: наиболее заселены равнинный и внутригорные части Дагестана, что объясняется их обширностью и удобством освоения. Предгорный и приморский яруса также характеризуются довольно удобными условиями для заселения и ведения хозяйства, в отличие от высокогорий. Однако удельная величина заселенности наиболее высока в приморском ярусе - 7,3\%, что указывает на наиболее благоприятные условия проживания населения и ведения хозяйства.

По состоянию на 2000 г. площадь населенных пунктов увеличилась до 953,2 км², то есть их удельный вес составил 1,9\%. Как и ранее, наибольшая площадь населенных пунктов отмечалась в пределах равнинного яруса - 380,2 км², или 1,8\%. Несмотря на то, что в 1990-е годы отмечался отток населения из горной части, площадь населенных пунктов в пределах внутригорного яруса возросла и составила 191,6 км², или 1,7\%. Отток населения наиболее сильно отмечался в пределах высокогорий, где площадь населенных пунктов составила 42,9 км$^{2}$. Что касается предгорного и приморского ярусов, то здесь площади, занятные под населенными пунктами, сопоставимы - 175,9 и 162,6 км², соответственно. Но при этом доля населенных пунктов составила 3,0\% в предгорьях и 11,0\% - в приморском ярусе.

То есть за это время произошло увеличение площади населенных пунктов на 193,0 км², или на 25,4\%. В абсолютном исчислении максимально увеличилась площадь населенных пунктов в пределах равнинного яруса, - на 91,7 км ${ }^{2}$, минимально - в пределах

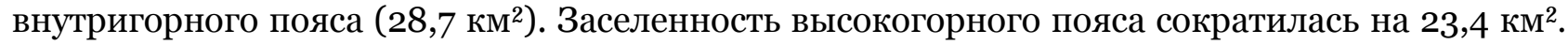
Не произошло никаких изменений в ранжировке площадей населенных пунктов по ландшафтно-геоморфологическим ярусам. Однако относительные тенденции изменения доли населенных пунктов иллюстрируют, что опережающими темпами происходило заселение приморского ландшафтно-геоморфологического яруса, где площадь НП увеличилась на 50,1\%. Практически близкими были темпы роста населенных пунктов в пределах равнинного и предгорного ярусов (31,8 и 31,2\% соответственно). Более медленный рост $(17,6 \%)$ отмечался в пределах внутригорного яруса, тогда как в высокогорьях произошло сокращение площади населенных пунктов на 35,3\%.

Для выяснения более тонких тенденций изменения площадей населенных пунктов также были проанализированы изменения данного параметра по категориям. На территории Республики Дагестан имеются традиционные для России категории населенных пунктов: города, поселки городского типа (ПГТ) и поселки сельского типа (ПСТ). Наряду с ними здесь имеются также поселки дачного типа, но, в силу их малочисленности и близости к городским поселениям, нами они были отнесены к категории поселков городского типа. Это связано с тем, что по особенностям внутренней пространственной структуры они близки именно к поселкам городского типа.

Изменение площади категорий населенных пунктов на территории Республики Дагестан иллюстрирует табл. 2. 
Изменение площади населенных пунктов по категориям (км²)

\begin{tabular}{|l|r|r|r|r|r|r|r|r|r|}
\hline \begin{tabular}{c} 
Ландшафтно- \\
геоморфологические \\
\multicolumn{1}{c|}{\begin{tabular}{r} 
ярусы \\
\cline { 2 - 10 }
\end{tabular}}
\end{tabular} & \multicolumn{3}{|c|}{ Города } & \multicolumn{3}{c|}{ ПГТ } & \multicolumn{3}{c|}{ ПСТ } \\
\hline Равнинный & $\mathbf{1 9 9 0}$ & $\mathbf{2 0 0 0}$ & $\boldsymbol{\Delta}$ & $\mathbf{1 9 9 0}$ & $\mathbf{2 0 0 0}$ & $\boldsymbol{\Delta}$ & $\mathbf{1 9 9 0}$ & $\mathbf{2 0 0 0}$ & \multicolumn{1}{c|}{$\boldsymbol{\Delta}$} \\
\hline Приморский & 37,7 & 60 & 22,3 & 17,8 & 30,1 & 12,3 & 233,0 & 290,1 & 57,1 \\
\hline Предгорный & 40,9 & 66,7 & 25,8 & 16,1 & 20,9 & 4,8 & 51,4 & 75,0 & 23,6 \\
\hline Внутригорный & 10,6 & 12,1 & 1,5 & 3,6 & 8,3 & 4,7 & 119,9 & 155,5 & 35,6 \\
\hline Высокогорный & & & & 2,0 & 2,6 & 0,6 & 161,0 & 189,1 & 28,1 \\
\hline & & & & & & & 66,4 & 42,8 & $-23,4$ \\
\hline
\end{tabular}

Примечание: $\Delta$ - изменение.

В разрезе типов населенных пунктов города размещаются в пределах равнинного, приморского и предгорного ярусов. За рассматриваемый промежуток времени площадь городов увеличилась на $49,7 \mathrm{KM}^{2}$. С учетом того, что приморский ярус минимальный по площади, а прирост здесь составил 25,8 км$^{2}$, можно констатировать, что здесь отмечается наибольший удельный рост площади городов. Как уже ранее отмечалось, наибольшие темпы роста отмечаются в пределах Махачкалинско-Каспийской агломерации [9].

Поселки городского типа, наряду с равнинным, приморским и предгорным, имеются также и в пределах внутригорного ландшафтно-геоморфологического яруса. Их площадь увеличилась с 39,4 до 61,9 км$^{2}$, или почти на 1/3. С точки зрения абсолютных величин, максимальный прирост отмечается в пределах равнинного яруса, однако наибольший удельный рост характерен для приморского.

Поселки сельского типа занимают максимальную, по сравнению с другими категориями населенных пунктов, площадь во всех ландшафтно-геоморфологических ярусах. За рассматриваемый временной отрезок их площадь увеличилась с 631,7 до 752,5, или на 120,8 км². Однако если в высокогорном ярусе отмечалось сокращение площади населенных пунктов (до 1/3), то в пределах остальных ярусов отмечается рост площади сельских населенных пунктов: в абсолютных величина - в пределах равнинного яруса, а в удельных - приморского и предгорного.

\section{Заключение}

Таким образом, наиболее притягательным для размещения населения на территории Республики Дагестан являются приморский и равнинный высотно-геоморфологические ярусы: здесь отмечается максимальная концентрация населения. Результатом этих процессов является формирование опорного центра расселения - МахачкалинскоКаспийской агломерации, где сосредоточивается основная часть населения республики.

\section{Благодарности}

Работа выполнена при финансировании по Тематическому плану Министерства образования и науки Российской Федерации (Номер темы 2374).

\section{Примечания:}

1. Акаев Б.А., Атаев 3.В., Гаджиева З.Х. и др. Физическая география Дагестана: Учебное пособие для студентов. М.: Школа, 1996. 384 с.

2. Атаев 3.В., Братков В.В. География и региональные особенности пространственной дифференциации и селитебной освоенности ландшафтов Северного Кавказа // Известия Дагестанского государственного педагогического университета. Естественные и точные науки. 2013. № 2 (23). С. 85-95.

3. Атаев 3.В., Братков В.В. Динамика селитебной освоенности ландшафтов формирующейся Махачкалинско-Каспийской агломерации (на основе данных дистанционного зондирования) // Мониторинг. Наука и технологии. 2013. № 4. С. 11-16. 
4. Атаев 3.В., Братков В.В., Гаджимурадова 3.М. Геоморфологическая дифференциация ландшафтных поясов Дагестана // Мониторинг. Наука и технологии. 2013. № 4. С. 7-10.

5. Атаев 3.В., Братков В.В., Заурбеков Ш.Ш., Астапов М.Б., Мамонов А.А. Селитебная нагрузка на ландшафты Северного Кавказа // Юг России: экология, развитие. 2012. № 4. C. 100-107.

6. Атаев 3.В., Заурбеков Ш.Ш., Братков В.В. Современная селитебная освоенность ландшафтов Северо-Восточного Кавказа // Известия Дагестанского государственного педагогического университета. Естественные и точные науки. 2010. № 1 (10). С. 71-74. 1999.

7. Атлас Республики Дагестан. М.: Федеральная служба геодезии и картографии России.

8. Мамонов А.А., Атаев 3.В., Братков В.В. Тенденции изменения селитебной освоенности ландшафтов Дагестана // Известия Дагестанского государственного педагогического университета. Естественные и точные науки. 2013. № 3 (24), С. 99-105.

9. Мамонов А.А., Братков В.В. Оценка изменения площади города Махачкала на основе данных дистанционного зондирования // Всероссийская научно-практическая конференция, посвященная 150-летию со дня рождения В.И. Вернадского «Современные проблемы геологии, географии и геоэкологии (секция географии). Грозный, 25-28 марта 2013 года. Махачкала: АЛЕФ, 2013. С. 126-128.

10. Мамонов А.А., Братков В.В., Атаев 3.В. Оценка изменения селитебной освоенности ландшафтов контактной полосы Терско-Сулакской и Приморской низменностей Дагестана на основе данных дистанционного зондирования // Известия Дагестанского государственного педагогического университета. Естественные и точные науки. 2013. № 1 (22). С. 84-89.

11. Мильков Ф.Н. Человек и ландшафты. М.: Мысль, 1973. 224 с.

12. Хрусталев Ю.П. Эколого-географический словарь. / Научн. редактор Г.Г. Матишов. Батайск, 2000. 198 c.

13. Atayev Z.V., Bratkov V.V. Modern Trends of Change of Residential Development of the Landscapes of Dagestan // European Geographical Studies. 2014. № 1(1). P. 4-11.

14. Atayev Z.V. Residential Development of the Dagestan Landscapes // The First International Conference on Eurasian scientific development. Vienna, 2014. P. 14-21.

15. Панков С.В. Степень селитебности физико-географических районов Тамбовской области // Вестник Тамбовского университета. Серия: Естественные и технические науки. 2010. T. 15. № 2. C. 620-623.

\section{References:}

1. Akaev B.A., Ataev Z.V., Gadzhieva ZKh. i dr. Fizicheskaya geografiya Dagestana: Uchebnoe posobiedlya studentov. M. : Shkola, 1996. $384 \mathrm{~s}$.

2. Ataev Z.V., Bratkov V.V. Geografiya i regional'nye osobennosti prostranstvennoy differentsiatsii i selitebnoy osvoennosti landshaftov Severnogo Kavkaza // Izvestiya Dagestanskogo gosudarstvennogo pedagogicheskogo universiteta. Estestvennye i tochnye nauki. 2013. № 2 (23). S. 85-95.

3. Ataev Z.V., Bratkov V.V. Dinamika selitebnoy osvoennosti landshaftov formiruyushcheysya Makhachkalinsko-Kaspiyskoy aglomeratsii (na osnove dannykh distantsionnogo zondirovaniya) // Monitoring. Nauka i tekhnologii. 2013. № 4. S. 11-16.

4. Ataev Z.V., Bratkov V.V., Gadzhimuradova Z.M. Geomorfologicheskaya differentsiatsiya landshaftnykh poyasov Dagestana // Monitoring. Nauka i tekhnologii. 2013. № 4. S. 7-10.

5. Ataev Z.V., Bratkov V.V., Zaurbekov Sh.Sh., Astapov M.B., Mamonov A.A. Selitebnaya nagruzka na landshafty Severnogo Kavkaza // Yug Rossii: ekologiya, razvitie. 2012. № 4. S. 100-107.

6. Ataev Z.V., Zaurbekov Sh.Sh., Bratkov V.V. Sovremennaya selitebnaya osvoennost' landshaftov Severo-Vostochnogo Kavkaza // Izvestiya Dagestanskogo gosudarstvennogo pedagogicheskogo universiteta. Estestvennye i tochnye nauki. 2010. № 1(10). S. 71-74.

7. Atlas Respubliki Dagestan. M.: Federal'naya sluzhba geodezii i kartografii Rossii. 1999.

8. Mamonov A.A., Ataev Z.V., Bratkov V.V. Tendentsii izmeneniya selitebnoy osvoennosti landshaftov Dagestana // Izvestiya Dagestanskogo gosudarstvennogo pedagogicheskogo universiteta. Estestvennye i tochnye nauki. 2013. № 3 (24). S. 99-105.

9. Mamonov A.A., Bratkov V.V. Otsenka izmeneniya ploshchadi goroda Makhachkala na os-nove dannykh distantsionnogo zondirovaniya // Vserossiyskaya nauchno-prakticheskaya konferentsiya, posvyashchennaya 150-letiyu so dnya rozhdeniya V. I. Vernadskogo «Sovremennye problemy geologii, 
geografii i geoekologii (sektsiya geografii). Groznyy, 25-28 marta 2013 goda. Makhachkala: ALFF, 2013. S. 126-128.

10. Mamonov A.A., Bratkov V.V., Ataev ZV. Otsenka izmeneniya selitebnoy osvoennosti landshaftov kontaktnoy polosy Tersko-Sulakskoy i Primorskoy nizmennostey Dagestana na osnove dannykh distantsionnogo zondirovaniya // Izvestiya Dagestanskogo gosudarstvennogo pedagogicheskogo universiteta. Estestvennye i tochnye nauki. 2013. № 1(22). S. 84-89.

11 Mil'kov F.N. Cheloveki landshafty. M.: Mysl', 1973. 224 s.

12. Khrustalev Yu.P. Ekologo-geograficheskiy slovar'. / Nauchn. redaktor G.G. Matishov. Bataysk, 2000. $198 \mathrm{~s}$.

13. Atayev ZV., Bratkov V.V. Modern Trends of Change of Residential Development of the Landscapes of Dagestan // European Geographical Studies. 2014. № 1(1). P. 4-11.

14. Atayev ZV. Residential Development of the Dagestan Landscapes // The First International Conference on Eurasian scientific development. Vienna, 2014. P. 14-21.

15. Pankov S.V. Stepen' selitebnosti fiziko-geograficheskikh rayonov Tambovskoy oblasti // Vestnik Tambovskogo universiteta. Seriya: Estestvennyei tekhnicheskie nauki. 2010. T. 15. № 2. S. 620-623.

УДК 332.36

\title{
Современные тенденции изменения селитебной освоенности ландшафтно-геоморфологических ярусов Республики Дагестан
}

\author{
${ }^{1}$ Виталий Викторович Братков \\ 2,3 Загир Вагитович Атаев
}

\author{
${ }^{1}$ Московский государственный университет геодезии и картографии, Российская Федерация \\ 105064, Москва, Гороховский переулок, 4 \\ Доктор географических наук, профессор \\ E-mail: vratkov@mail.ru \\ 2 Дагестанский государственный педагогический университет, Российская Федерация \\ 3670о3, Махачкала, улица Ярагского, 57 \\ ${ }^{3}$ Прикаспийский институт биологических ресурсов Дагестанского научного центра \\ Российской академии наук, Российская Федерация \\ 3670о0, Махачкала, улица Гаджиева, 45 \\ Кандидат географических наук, профессор \\ E-mail: zagir05@mail.ru
}

Аннотация. В статье выявлены тенденции изменения селитебной нагрузки в пределах ландшафтно-геоморфологические ярусов Республики Дагестан. Анализ проведен на основе сопоставления площадей населенных пунктов разных категорий по картам среднего масштаба изданий середины 1980-х и начала 2000-х годов. Выявлены тенденции изменения площади населенных пунктов и их категорий по высотно-геоморфологическим ярусам. За рассматриваемый промежуток времени селитебная нагрузка снизилась лишь в пределах высокогорного яруса, тогда как в остальных она возросла. В наибольшей степени рост нагрузки характерен для приморского и равнинного ярусов, где активно формируется Махачкалинско-Каспийская агломерация.

Ключевые слова: республика Дагестан; ландшафтно-геоморфологические яруса; населенный пункт; селитебный ландшафт; селитебная нагрузка. 